Sivakumar Santhana Prabha ${ }^{1}$, Rajendran Joseph Rathish ${ }^{1}$, Suresh Jancyrani', Susai Rajendran ${ }^{* 3}$, Abdulhameed AlHashem $^{4}$, Rajendran Dorothy ${ }^{5}$, Thiruppathi Raja Umasankareswari ${ }^{6}$

${ }^{1} P S N A$ College of Engineering and Technology, Dindigul, India, ${ }^{2} P G$ Department of Chemistry, MV Muthia Government Arts College for Women, Dindigul, India, ${ }^{3}$ Corrosion Research Centre, St. Antony's College of Arts and Sciences for Women, Thamaraipadi, Dindigul, Indai, ${ }^{4}$ Senior Research Scientist, Petroleum Research Centre, Kuwait Institute for Scientific Research, Kuwait, ${ }^{5}$ AMET University, Department of EEE, Chennai, India, 'Department of Chemistry, Rajapalayam Rajus' College, Rajapalayam, India
Review paper

ISSN 0351-9465, E-ISSN 2466-2585 UDC: $620.193 .7+620.193 .22: 681.527$ doi: $10.5937 /$ zasmat1903259S

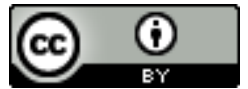

Zastita Materijala 60 (3) $259-270$ (2019)

\title{
Corrosion problems in electronic systems
}

\begin{abstract}
Microelectronics and, chiefly, silicon integrated circuit microelectronics, has created astonishing capabilities over the last 40 years. Speedy advancement in CMOS transistor equipment leading to the gigahertz speeds common today has necessitated chief changes in semiconductor manufacturing technology and the expansion of high frequency compatible packaging. The progress of an optimized formulation for electroless nickel (EN) plating with a long life span to make a deposit with good corrosion resistance $(C R)$. The electroless deposition of Ni-P alloys is widely used in diverse fields such as aerospace, automation, electronics, nuclear, oil and gas production, and valve industries. Lead frame is the primary package metallurgical bond pad interface in microelectronic devices which provides external interconnection. The most predominant lead frame material is copper with tin plating. Over the years, galvanic corrosion and copper oxidation are two major reliability concerns for any microelectronics packages with copper lead frame, when operating under high humidity environment.
\end{abstract}

Keywords: electronics, corrosion, bimetallic corrosion, electronic components, silver bonding.

\section{INTRODUCTION}

With the combined augment in shrinking of electronic systems and also the explosive increase in their convenience, it is probable that the corrosion and decline of electronics can become a social group issue with dire unpredictable consequences. Corrosion mechanisms in electronic parts are the topic of in depth studies. Since electronics are for the most part found inside or among enclosures, the mechanisms resulting in corrosion issues are not simply outlined. Issues are combined by the very fact that these systems are unreal by variety of complicated processes and accommodate a range of dissimilar materials. Shrinking and also the demand for top part density has resulted in smaller parts, nearer spacing, and diluent metallic methods. Consequently, the result of bias potentials and tiny defects is enlarged.

\footnotetext{
${ }^{*}$ Corresponding author: Susai Rajendran

E-mail: susairajendran@gmail.com

Paper received: 13. 05. 2019.

Paper accepted: 26. 05. 2019.

Paper is available on the website:

www.idk.org.rs/journal
}

\subsection{Manifestation of Corrosion in electronic components}

Corrosion in electronic parts manifests itself in several ways. Computers, integrated circuits, and microchips are currently an integral part of all technology-intensive business product, starting from part and automotive to medical instrumentation and client product, and are thus exposed to a range of environmental conditions. Corrosion in electronic components are insidious and may not be promptly detected. Consequently, once corrosion failure happens, it is typically dismissed as simply a failure and therefore the half or element is replaced. Thanks to the issue to discover and determine corrosion failures, the value of corrosion is hard to detect and identify corrosion failures, the cost of corrosion is difficult to determine.

\subsection{Materials used in electronic components}

Materials utilized in electronic parts vary from aluminum-based alloys (integrated circuits conductors) to copper contacts electroplated with nickel or gold for improved resistance. Submicron dimensions of electronic circuits, high-voltage gradients, and a particularly high sensitivity to 
corrosion or corrosion product gift a singular set of corrosion-related problems. A significant departure from most corrosion things is that the implausibly little volume of the fabric that may be broken and result in a fault. The semiconductor in Associate in Nursing automobile, for instance, isn't directly subjected to the identical environmental hazards because the automotive body. However, the tolerance for corrosion loss in electronic devices is several orders of magnitude less, i.e. on the order of picograms $\left(10^{-12} \mathrm{~g}\right)$. Minimum line dimension within the progressive computer circuit boards (PCBs) in 1997 was but a hundred m. On hybrid integrated circuits (HICs), line spacing could also be but $5 \mu \mathrm{m}$.

Recent electronics includes a broad range of machines such as various size computers with main memory, storage devices, input and output devices, telecommunication equipment, various purpose instruments and more or less sophisticated consumer electronic devices. The metallic parts may undergo corrosion since they are exposed to moisture most of the time. Moreover, when various metals and alloys are joined through welding there is chance for bimetallic corrosion. Many researches are on anvil in this area. The recent trends in research on corrosion problems in electronic equipments are presented.

\section{RECENT ADVANCEMENTS IN CORROSION PROBLEMS IN ELECTRONIC INDUSTRY}

\subsection{Advancements in silver wire bonding}

Silver is a leading contestant to gold and copper in fine pitch wire bonding used in the interconnection of microelectronic devices. Most important material for wire bonding has been gold, which gave way to copper in order for original equipment manufacturers to realize cost benefits. Nevertheless, copper wire bonding has exhibited several reliability issues, especially in industrial and high temperature applications. Corrosion is the major problem, which was mitigated by coating the wire with palladium, which increased overall cost of production. Other concerns include harder free air ball ( $F A B$ ) leading to under pad metallization cracking, smaller process window, excessive aluminum splash especially in fine pitch bonding, and lower throughput and yield arising from the rigidity and stiffness of copper. Due to the above concerns, automotive, armed and aerospace industries are still reluctant to fully adopt copper wire bonding. Light emitting diodes (LEDs) are also not manufactured with copper wires due to its low reflectance. Some of these industries are still using gold wire bonds in most of their packages, but are continually looking for an alternative. Silver wire bonds have high-quality electrical and thermal conductivity, are less prone to corrosion than copper, have low melting points and comparable hardness to gold. Also, cost of silver has been shown to be similar to that of palladium coated copper wire, hence making it a good alternative. Silver wire bonding, a relatively new area of research, has attracted a lot of research focused on wire dopant matter, bonding process, excellence and trustworthiness [1].

\subsection{Improving corrosion resistance via graphene nanocomposite coatings}

The defeat of material properties due to environmental effects such as ultraviolet (UV) light, moisture, and oxygen has been a long-standing problem. To address this issue, materials are often coated with polymeric substances. Even though polymers offer enhanced resistance against environmental degra dation, they are not a comprehensive solution to overcoming the problem since over a protracted period of time, the coatings themselves are susceptible to various environmental conditions. Current research studies have been aimed at improving the resistance of coatings against such dreadful conditions using nano materials. In order to achieve such enhancement, the use of graphene nanoflake reinforcement in polymeric coatings has newly been investigated by many scientists. Graphene nano flakes were chosen mainly because of their excellent chemi cal inertness, tensile strength (150 GPa), Young's modulus (1.0 TPa), thermal conductivity (4840$5300 \mathrm{~W} / \mathrm{m} \mathrm{K})$, electrical conductivity (1.3 × 106 $\mathrm{S} / \mathrm{cm})$, electrical current density $\left(1013 \mathrm{~A} / \mathrm{cm}^{2}\right)$, and optical transmittance $(97.7 \%)$. It was hypothesized that graphene could act as a strong blocking agent and augment the resistance of coatings against UV light, moisture, oxygen, and so on [2].

\subsection{New surface finish for the electronics industry:}

\section{Electroless nickel/immersion silver}

The presentation expectations for printed circuit board, surface finishes are better than just solderability conservation. In history, final finishes were designed solely to protect copper from oxidation prior to the soldering of components. Now the opportunities are much greater; better solderability, contact performance, wire bondability, corrosion resistance, and all this must be achieved at low cost. For the past few years the electronics industry has been investigating the effects of harsh environments on printed circuit assemblies. The general consensus is that the environments electronics experience today are particularly aggressive, being regularly exposed to high levels of contaminants such as sulfur, sulfide, $\mathrm{SO} x$ and NO $x$. One frequent surface finish now often used in the electronics manufacturing is immersion 
silver. The fame of this technology has increased over the last decade and now accounts for about $10 \%$ of the final finish market. The popularity of immersion silver is driven by factors such as, excellent solderability, very low contact resistance; easy of assembly and testing, and it is a relatively low cost option. As mentioned above, electronic components are now often exposed to harsh, corrosive environmental and use conditions. Long term exposure to such environments can result in the onset of varying degrees of corrosion phenomena, such as creeping corrosion, peeling and coating tarnish. These phenomena can be mitigated by the adoption of best application practices and assembly processing, in conjunction with the use of specially formulated anti-corrosion coatings. An another final finish regularly used for high reliability applications is electroless nickel/immersion gold (ENIG), however this technology also is not without its problems, a general example, which can arise through the use of a poorly formulated process, is 'black line nickel'. This issue has been a concern to the electronics industry for some time and has hurt the status of ENIG as a final finish, limiting in some cases its wider adoption. With this in mind, coupled with the very high price gold currently achieves on the open market (in excess of 1300 per troy ounce) the industry is looking for an alternative technology. Recently restrictions on cyanide in certain regions of the world have also put pressure on those using ENIG. Ideally, a suitable alternative would retain the positive features of the ENIG finish whilst, at the same time, eliminate the black line nickel concern and be much more economical without the use of cyanide. This paper details such a process; electroless nickel/immersion silver. Careful choice of the electroless nickel and immersion silver processes result in a surface finish that has superior function, performance and is low cost [3].

\subsection{The influence of autoclave on plastic encapsulated microcircuit}

Plastic encapsulated microcircuit (PEM) is widely used due to its great advantages in size, weight, cost and performance, especially in industries. However, there are many troubles that cannot be ignored. The most significant one is that PEM is not hermetical, which means that moisture can infiltrate in the PEM. The infiltration may lead to the delamination, even result in corrosion. Autoclave is one of the powerful reliability tests applied mainly to evaluate the moisture resistance integrity of non-hermetic packaged. The PEM is subjected to a condensing, highly humid surroundings under pressure to force moisture into the package. In this paper, the influence of autoclave on plastic encapsulated microcircuit is deeply discussed. Totally 80 PEMs from 8 devices are used as samples, containing different companies (TI, NXP, IDT, etc), different packages (TSSOP, SOIC, BGA, etc.) and special operating temperature scales (-55D 125D, -40D 85D, etc.). Before autoclave, scanning acoustic microscope (SAM) is used to check the delamination. Then, autoclave is operated. After $48 \mathrm{~h}$ autoclave, delamination between plastic mold and silicon chip can be observed in some of the samples obviously. In the meantime, the leads of few samples are oxidized. Followed with another 48 hours autoclave, the degree of delamination is extended and oxidizing material can be seen not only on the leads, but also on the surface. When autoclave operated to $168 \mathrm{~h}$, the delamination is more grave. What is more, some samples failed in the electrical characteristic test. Failure analysis is operated afterwards. The result shows that there are many factors may have contributed to the failures. The most important one is strongly related to the delamination of molding compound and passivation glass on the surface of the die. The oxidizing material also plays a very important role to the breakdown[4].

\subsection{Progress in magnesium alloys reinforced by long period stacking ordered structure}

With the quick development of automobile and aviation industries, higher-performance light quality magnesium alloys for energy-saving emission and lightweight exhibited great development. The excellent effect of solid solution and precipitation of rare earth elements could help to improve the strength, creep resistance, and corrosion resistance at high temperature of alloys, play a role of hydrogen deoxidation to improve casting properties remarkably. The growth of rare earth magnesium alloys would have a bright prospect for application in fields such as aerospace, electronics, automobile, communication and so on. In recent years $\mathrm{Mg}$-RE alloys by adding $\mathrm{Zn}, \mathrm{Cu}, \mathrm{Ni}$ or other elements, adjusting alloy composition, temperature and cooling conditions reasonably, could form an ordered solid solution with a long period stacking ordered (LPSO) structure. After severe plastic deformation, the allocation of LPSO phrase was dispersed and uniform in $\mathrm{Mg}$ matrix which was refined at the same time. The process greatly improved the tensile strength and toughness. As a new kind of efficient reinforcement in magnesium alloys, LPSO structure could improve mechanical properties significantly, and exhibited a great development prospect. existing research and application status of magnesium alloys with the long period stacking ordered structure were reviewed mostly on development status of Mg-RE$\mathrm{Zn}, \mathrm{Mg}-\mathrm{RE}-\mathrm{Cu}, \mathrm{Mg}-\mathrm{RE}-\mathrm{Ni}$ alloy series worldwide. 
The main problems and the trend of magnesium alloys with the long period, tacking ordered structure were proposed [5].

\subsection{Reuse of hazardous calcium fluoride sludge from the integrated circuit industry}

The Chinese integrated circuit industry has been transformed from a small state-owned sector into a global competitor, but chip manufacturing produces huge amounts of calcium fluoride sludges (CFS). In China, landfill is a current option for treating CFS. In order to solve the problem of unavailable landfill sites and prevent fluorine from dissolved CFS polluting water sources, CFS was tested as a component for a ceramic product made with sodium borate, sodium phosphate and waste alumina using a low-temperature sintering technology, and the effects of various factors on characteristics of the ceramic were investigated to optimize the method. The best sintering temperature was controlled at $700^{\circ} \mathrm{C}$, and the optimal raw material ratio of the ceramic was $11 \%$ sodium borate, $54 \%$ sodium phosphate, $30 \%$ CFS and $5 \%$ waste alumina. The CFS ceramic was characterized by a morphological arrangement and $X$-ray diffraction. The results indicated that CFS was transformed into $\mathrm{Na}_{2} \mathrm{Ca}\left(\mathrm{PO}_{4}\right) \mathrm{F}$ as an inert and a chief crystalline phase in the ceramic, which was enclosed by the borophosphate glass. Toxicity characteristic leaching process, corrosion resistance and compressive strength tests verified CFS ceramic as a qualified construction ceramic material, and the fluorine from CFS was solidified in the inert crystalline phase, which would not be released to cause secondary pollution. This novel technology not only avoids the CFS hydrolyzing reaction forming injurious hydrofluoric acid gas at $800^{\circ} \mathrm{C}$ and above, but also produces highperformance ceramics as a construction material, in accordance with the concept of sustainable development [6].

\subsection{Effect of the intermediate layer composition on tribocorrosion behavior of zinc-nickel alloy}

The industrial use of $\mathrm{Zn}-\mathrm{Ni}$ alloys in steel objects - in which tribocorrosion must be taken into account - has significant importance, especially in the automotive industry, aircraft industry and electronics. The tribocorrosion failure of $\mathrm{Ni}-\mathrm{Zn}$ alloy coated steel parts can cause major economical damages and grave operational problems in some structures. The effect of intermediate layer between the steel and the top $\mathrm{Zn}-\mathrm{Ni}$ coating on the tribocorrosion performance was examined in $1 \%$ $\mathrm{NaCl}$ solution with "cylinder-on-plate" tribometer technique, while the measurements of electrochemical and frictional forces were performed in real-time. The composition of the intermediate layer affects the tribocorrosion resistance, proving the negative potential shift in open circuit [7] .

\subsection{Decapsulation methods for $\mathrm{Cu}$ interconnection packages}

Decapsulation is the procedure of removing mold compound from the die surface of a plastic encapsulated device. Typically, the mold compound is removed only in the area above the die and bond wires for failure site isolation and analysis. Hot fuming sulfuric and nitric acids are the most normally used decapsulating agent. Jet etching system employing these acids or mixture of these acids have become the main method for decapsulation. However, due to the increase of the gold price, the IC industry has already begun to switch from gold wire bonding to copper wire bonding. However, the use of copper wires bonding also introduces a problem in failure analysis. The traditional encapsulation techniques of acid results in corrosion. Therefore, many improvements for wet chemical etching and dry etching methods are found such as laser and plasma methods [8].

\subsection{Influence of nitrogen and forming gas towards palladium coated copper wire}

Copper $(\mathrm{Cu})$ wire development started in the early 1980's as the cost for semiconductor manufacturing has become competitive and challenging with the increase of gold price. The lessons educated along the research and studies carried out, helped the industry to understand the subtleties and facts about $\mathrm{Cu}$ wire bonding process. The most general and significant facts about $\mathrm{Cu}$ wire bonding is its sensitivity towards oxidation. Studies showed that oxidized copper ball can contribute towards bond pad damages and further induced quality issues. In addition, bond pad galvanic corrosion with ball bond and CuAl diffusion is also the contributor towards the degradation of $\mathrm{Cu}$ wire quality. Research has been done by electroplating diverse material over the $\mathrm{Cu}$ wire. The studies showed that Pd-plated $\mathrm{Cu}$ wire doesn't give problems when forming the free air ball. This type of wire is named as "hybrid Bonding Wire". The discovery of this new metallurgy can prevent the oxidation as well as slowing down the intermetallic diffusion during reliability stress test, to improve 2nd bond process during wire bonding and improve stitch power [9].

\subsection{Moisture induced corrosion in gold and copper ball bonds}

High gold prices have led to renewed attention in replacing gold with copper in existing packages and new packages in order to save costs. Although reliability is often cited as a reason for using 
copper, the main driving force for its use is certainly cost. Perceptions that copper wire is more reliable are based on the notion that the intermetallics grow more slowly and that thinner intermetallics are more reliable and yet old data tend to support the idea that copper is as reliable as gold. More recently however, copper ball bonds on aluminium metallization have been found to fail more than gold during temperature cycling (TMCL) and pressure cooker testing (PCT). The key feature of these tests is the presence of wetness than appears to accelerate corrosion. A proposed solution to this problem is $\mathrm{Pd}$-coated $\mathrm{Cu}$ wire, which looks to be a promising but relatively untested solution at present. While Pd-coated copper wire may advance reliability, cost-savings will be less compared with bare copper wire. It is important to note however that a recent SEMI survey shows that industry is generally not as confident in copper as wire equipment and materials suppliers. Localized corrosion of aluminium bond pads is well known in microelectronics packaging and in $\mathrm{Al}-\mathrm{Cu}$ and $\mathrm{Al}$ $\mathrm{Cu}$-Si bond pads, $\mathrm{CuAl}_{2}$ acts as a cathode and aluminium corrodes in the presence of water (electrolyte). The situation is complicated by the presence of chlorine and other ionic contaminants in addition to moisture. In copper ball bonds, intermetallic coverage in as-bonded balls is very difficult to see but it appears that $\mathrm{CuAl}_{2}$ and $\mathrm{Cu}_{9} \mathrm{Al}_{4}$ are the compounds that form initially. Intermetallic growth of Cu-Al compounds is slow compared to $\mathrm{Au}-\mathrm{Al}$ compounds, which means that in finished packages, a large amount of $\mathrm{Al}$ remains whereas in gold ball bonds, with thin $1 \mathrm{~m}$ bond pads, aluminium can easily be consumed after encapsulation and moulding and surface mounting. It is plausible that during extended periods of exposure to moisture, stress and ionic contaminants, $\mathrm{Cu}$ ball bonds may be more vulnerable to localized corrosion than $\mathrm{Au}$ ball bonds because slow intermetallic growth permits aluminium corrosion [10].

\subsection{Microstructure and corrosion behavior of laser welded magnesium alloys with silver nanoparticles}

Magnesium alloys have gained increased attention in recent years in automotive, electronics, and medical business. This is because of magnesium alloys have superior properties than aluminum alloys and steels in respects of their low density and high strength to weight ratio. However, the main problems of magnesium alloy welding are the crack formation and the appearance of porosity during the solidification. A unique technique to weld two thin sheets of AZ31B magnesium alloy using a paste containing $\mathrm{Ag}$ nanoparticles has been proposed. The paste containing $\mathrm{Ag}$ nanoparticles of $5 \mathrm{~nm}$ in average diameter and an organic solvent was used to coat the surface of AZ31B thin sheet. The coated sheet was heated at $100{ }^{\circ} \mathrm{C}$ for $60 \mathrm{~s}$ to evaporate the solvent. The dried sheet was set as a lower AZ31B sheet on the jig, and then lap fillet welding was carried out by using a pulsed Nd:YAG laser in a closed box filled with argon gas. The characteristics of the microstructure and the corrosion behavior of the joints were analyzed by opticalmicroscopy (OM), energy dispersive spectrometry (EDS), electron probe micro-analyzer (EPMA), scanning electron microscopy (SEM), and immersion corrosion test. The experimental results show that the wrought AZ31B magnesium alloy can be joined fruitfully using $\mathrm{Ag}$ nanoparticles. $\mathrm{Ag}$ nanoparticles insert promote grain refinement, narrower the HAZ width and wider bond width compared to weld without and insert. Corrosion rate of welded AZ31B with $\mathrm{Ag}$ nanoparticles reduced up to $44 \%$ compared to base metal. The improvement of corrosion resistance of welded AZ31B with $\mathrm{Ag}$ nanoparticles due to finer grains and large grain boundaries area which consist of high Al content. $\beta$-phase Mg 17Al 12 could serve as effective barrier and suppressed further spread of corrosion. Furthermore, Ag distribution in fusion zone provide much more finer grains and may stabilize the magnesium solid solution making it less soluble or less anodic in aqueous [11].

\subsection{Nanofluids in a forced-convection liquid cooling system - Benefits and design challenges}

Nanofluids are gaining in reputation among academic researchers and receiving more attention from industry as they continue to demonstrate heat transfer improvements in liquid cooling processes. 'Nanofluids' is the accepted nomenclature for slurries containing a mixture of a base fluid and suspensions of nano-scale particulates, or nanoparticles. When nanofluids are used in a liquid cooling process, the purely convective mode of heat transfer with the base fluid alone now becomes a heat transfer problem with convection and conduction effects. The author have explored the use of nanofluids in a forced-convection liquid cooling system and presents several critical findings in experiments carried out at GE Healthcare's Magnetic Resonance Center. These findings include the heat transfer measurements as well as some of the aspects of nanofluids that need to be considered when integrating into a liquid cooling system. A forced convection experiment was used to characterize the heat transfer rate through a single-IGBT cold plate for $1.5 \% \mathrm{v} / \mathrm{v} \mathrm{CuO}$ and $1 \% \mathrm{v} / \mathrm{v} \mathrm{Al}_{2} \mathrm{O}_{3}$ nanofluid mixtures. Both the $\mathrm{CuO}$ and $\mathrm{Al}_{2} \mathrm{O}_{3}$ nanoparticles were manufactured to a 
nominal $30 \mathrm{~nm}$ diameter. The base fluid used was a specially formulated coolant with less than $0.07 \%$ of corrosion inhibitor and biocide and, for this paper, can be simply treated as water. Maximum convective heat transfer coefficient increases were $4.0 \%$ for $\mathrm{CuO}$ and $4.5 \%$ for $\mathrm{Al}_{2} \mathrm{O}_{3}$ over deionized water in the flow rate ranges tested. Additionally, required pumping power to achieve a maximum flow rate of $1.6 \mathrm{gpm}$ also increased over the base fluid. These increases were $7.5 \%$ for the $1 \% \mathrm{Al}_{2} \mathrm{O}_{3}$ and $40 \%$ for the $1.5 \% \mathrm{CuO}$ nanofluid mixtures. Several other important observations were made that significantly affect the viability of nanofluids making it into products that use forced-convection liquid cooling systems. Nanofluid and nanoparticle health risks are not yet totally understood. Proper handling and disposal of the small particles typically metal or metal oxides - must be carefully considered, as the particles are easily inhalable and capable of transferring through cellular junctures and tissue barriers. Additionally, integrating the nanofluids into existing forced-convection liquid cooling systems creates concerns for piping erosion, component harm, and nanoparticle settling or agglomeration [12].

\subsection{Magnesium and surface engineering}

Magnesium is fast becoming the material of choice across a wide cross-section of industries including aerospace, automotive, consumer electronics, defense and biomaterials. Low density, high strength-to-weight ratio are usually the prime reasons for specifying the use of magnesium alloys in engineering design applications such as aerospace. The traditional problems of magnesium are mainly inherently poor corrosion and scratch/ /wear resistance, thus restricting to only limited applications to date. Chemical conversion surface treatments such as chrome pickling or anodizing, in combination with organic sealing/coating systems, were extensively adopted in the past with some success in limited number of applications and most extensively used of these classically contained $\mathrm{Cr}(\mathrm{VI})$. A major source of $\mathrm{Cr}(\mathrm{VI})$ emission comes from chromic acid anodizing (CAA) and chromium conversion coating of aluminum and magnesium [13].

\subsection{Accounting for Heat Transfer Problems in the Semiconductor Industry}

Electronics has become all-pervading in our everyday lives. Occurring in all modern machines in the form of systems, functions, and components, it is gradually supplementing or replacing those functions previously carried out exclusively by mechanics, electromechanics, hydraulics, and pneumatics, by making the processes faster, more flexible, and safer in a quite impressive way, and enriching the interaction between human and machine, until it has become a key feature of novelty and competitively in all sectors of the economy. The preliminary 'electronification' of existing systems is quickly followed by ever more sophisticated attempts to integrate electronic components and functions as close as possible to the target information sources and the devices to be operated, positioning the information processing and storage centers (processor and memory) as judiciously as possible. In this way, all kinds of chip are taken away from the sheltered conditions of specialised containers and end up having to operate in whatever environment prevails at the heart of the system they are designed to serve. In high speed trains, the encapsulated chips of the power switches are in contact with the alternator, at temperatures that sometimes reach $300^{\circ} \mathrm{C}$, while those controlling car ignition must resist humidity and corrosion, and the power transistors in radars and lasers of on-board lidar systems have to function at high altitudes, at sea, or in the field[14].

\subsection{Modeling and analysis of a connector system for the prediction of vibration-induced fretting degradation}

It is usually recognized that vibration-induced fretting degradation can be a chief problem for connector systems used in vehicle electronics. An earlier initial study about vibration-induced fretting degradation was conducted for a blade/receptacle connector pair. However, in real industry application of the connector systems in vehicles, not single but sixteen pairs of pin connectors are sealed and served as an entire connector system. As a result, it would be of great value to develop and analyze the entire connector system to investigate the relative influence of connector system characters on fretting degradation problem. The present study is the next step in this effort. A simplified 2-D model and a detailed 3-D model were developed and compared using ABAQUS. A series of simulations were performed on the FEA model. Corresponding experiments were conducted to validate and test the simulation. It was demonstrated that, for this connector system, finite element modeling and analysis have great prospective for the prediction of the influence of design variation on the fretting degradation of the connector scheme [15].

\subsection{Non-contact stray current measurements in a multi-line, multi-crossing pipeline corridor}

Stray Current (SC) has been an area of concern to Cathodic Protection professionals since at least 1917 and in the intervening century it has only become a bigger trouble. The three biggest causes of increased CP interference is the increased use 
of underground usefulness construction, increased oil and gas exploitation, and increased number of electric rail systems. While analyzing the effects of $\mathrm{SC}$ is straightforward. methods of analyzing the problem are rather difficult. Specifically, gathering the data was an inefficient process. Measuring potentials gave an unfinished picture of what was happening and measuring current was difficult. Current electronics and software assists in the ease of gathering enough data to assess SC and helping make the information more easily analyzed. The major advancement may be non- contact test methods and the ability to accurately measure DC currents [16].

\subsection{Study of texture evolution during channel-die compression of MG-AL alloys by in-situ neutron diffraction}

The noteworthy weight saving afforded by magnesium alloys has been established in many research projects in the automotive, aviation, machine tool, and consumer electronics industries. Major problems in the large-scale application of magnesium alloys are poor formability, low corrosion resistance, and creep. The properties of magnesium can be improved dramatically by the addition of a broad variety of alloying elements. Casting, downstream operation, and heat treatment are all effective tools in achieving optimized material presentation at a competitive cost. Although these significant mechanical properties can be strongly affected by crystallographic texture, there is little in the way of indepth studies have been reported in the literature. Mainly, improvements in properties reported are rarely supported by an analysis of the corresponding modification of the texture. The present study contributes to the general understanding of texture evolution during rolling of binary Mg-Al alloys. A jig for hightemperature in-situ channel die compression has been designed and fabricated at the Canadian Neutron Beam Centre (CNBC) with a purpose to simulate industrial rolling operation. The high penetrating power of neutrons allows data to be collected from the alloy during deformation. It is shown that the observed texture evolution can be attributed to a combination of $\{1012\}$ twinning and basal slip [17].

\subsection{Reliability of microelectronic packages with tin-plated copper leads under high humidity operating environment}

Lead frame is the primary package metallurgical bond pad interface in microelectronic devices which provides external interconnection. The most predominant lead frame material is copper with tin plating. Over the years, galvanic corrosion and copper oxidation are two major reliability concerns for any microelectronics packages with copper lead frame, when operating under high humidity environment. In their reliability lab, the authors often encountered corrosion and oxidation on the leads backside of certain devices which had undergone autoclave stress. Often, this observation is correlated to the rise in drain-tosource on-resistance. Failure analysis result revealed that non-homogeneous tin plating is the contributing factor. In the past, the operators utilized conventional cleaning method, that is, polished leads backside with sandpaper followed by acetone rinse. However, this could not remedy the problem efficiently [18].

\subsection{Large area distributed electronics}

Microelectronics and, chiefly, silicon integrated circuit microelectronics, has created astonishing capabilities over the last 40 years. There are many indicators of this, but best summarized as "Moore's Law." While more transistors $/ \mathrm{cm}^{2}$ is the driving force, the microelectronics-based display industry has, for over a decade also explored alternate directions - larger and larger "chips" and/or alternative substrates. Thus, displays have grown from several in 2 to several $\mathrm{ft} 2$ while the number of transisors $/ \mathrm{cm}^{2}$ has remained small. Further, major $R$ \& $D$ investment has been made in migrating from a glass substrate "chip" to a plastic one in order to achieve increased functionality (again without increasing the transistors $/ \mathrm{cm}^{2}$ ) [19].

\subsection{Impact of Low K dielectrics on microelectronics reliability}

Speedy advancement in CMOS transistor equipment leading to the gigahertz speeds common today has necessitated chief changes in semiconductor manufacturing technology and the expansion of high frequency compatible packaging. Current microcircuits may have eight metal layers, each separated by only 0.1 micrometers. RC delays and cross talk rather than transistor speed are now the major performance limitations. The semiconductor business has responded by increasing copper metallization to replace aluminum and lower dielectric constant materials to replace silicon oxide. Within the last decade the industry has shifted from fully integrated production to the fabless model of IC manufacture for all but a few large companies. Fabless manufacturers use separate commodity suppliers for wafer fabrication, assembly and test, resulting in poor understanding and control of these key stages of getting a product to market. This has had solemn implications for timely product introduction and dependability. Often, afabless company design team simply handed off good die from their contract foundry to a 
packaging group or off-shore assembler with little thought of consistency. Habits are changing, but the evolution has been very slow. Some new packaging options impose increased mechanical and thermal stresses on the microcircuits, while the low-k dielectrics are considerably weaker than traditional dielectrics. Major reliability hazards include delamination and cracking in the interconnection stack of metals and dielectrics above the active circuitry. Corrosion of metals can also occur after moisture enters through the defective insulation. SEM cross sections will be used to exemplify real problems that have been observed during structural and failure analyses performed on production devices [20].

\subsection{Who are we kidding?}

The consumer industry is taking efficient measures to work safely and advantage from contemporary electronic gadgets, which eventually provide with a better and safer way of life. The industry introduces new, improved products almost annually, depending on the application, thereby significantly contributing to the economic growth. Key personnel should have proper process knowledge and hands-on experience of no-clean products to encourage the advances of the modern electronic products. Increasing awareness is also being focused on the long-term reliability of the assembled products, while the production process changes required for the introduction of lead-free solders have been investigated intensely. The use of an effortlessly cleanable paste for removing residues also is a valuable alternative for cleaning, and this serves as a guarantee that even after years in the field, there will be no troubles with the assembly, such as corrosion and delamination of conformal coatings [21].

\subsection{High corrosion-resistant and long-life-span electroless nickel process}

The progress of an optimized formulation for electroless nickel (EN) plating with a long life span to make a deposit with good corrosion resistance (CR), is discussed. The electroless deposition of $\mathrm{Ni}-\mathrm{P}$ alloys is widely used in diverse fields such as aerospace, automation, electronics, nuclear, oil and gas production, and valve industries. To remove the problems of EN solution under unstable condition of thermodynamics, stabilizers were used that involves heavy metal ions, negative ions of inorganic oxygen acid and organic compounds. It was found that with the rising temperature, the deposit rate becomes higher, but the steadiness of EN solution becomes poorer when temperature is over $95^{\circ} \mathrm{C}[22]$.

\subsection{Primary response of high-aspect-ratio thermoresistive sensors}

There is a mounting need for sensors in monitoring performance in current excellence products such as in electronics to monitor heat build up, substrate delaminations, and thermal runaway. In processing instruments, intelligent sensors are needed to measure deposited layer thickness and resistivities for process control, and in environmental electrical enclosures, they are used for climate monitoring and control. A yaw sensor for skid prevention utilizes very fine moveable components, and an automobile engine controller blends a microprocessor and sensor on the same chip. An Active-Pixel Image Sensor is integrated with a digital readout circuit to perform most of the functions in a video camera. Magnetostrictive transducers sense and damp vibrations. Enhanced acoustic sensors will be used in flow detection of air and other fluids, even at subsonic speeds. Optoelectronic sensor systems are being developed for installation on rocket engines to monitor exhaust gases for signs of wear in the engines. With new freon-free coolants being available the problems of $A / C$ system corrosion have gone up in automobiles and need to be monitored more frequently. Defense cutbacks compel the storage of hardware in safe-custody for an indeterminate period of time, and this makes monitoring more essential. Just-in-time customized manufacturing in modern industries also needs dramatic adjustment in productivity of various selected items, leaving some manufacturing equipment idle for a long time, and therefore, it will be prone to more corrosion, and corrosion sensors are needed. In the medical device industry, expansion of implantable medical devices using both potentiometric and amperometric determination of parameters has, until now, been used with insufficient micro miniaturization, and thus, requires surgical implantation. In several applications, high-aspect- ratio devices, made possible by the use of synchrotron radiation lithography, allow additional useful devices to be produced. High-aspect-ratio sensors will permit industries and various other users to attain additional accurate measurements of physical properties and chemical compositions in many systems. Considerable engineering research has recently been focused on this type of fabrication consequence [23].

\subsection{Clean laboratories: Past, present and future}

Clean chemistry laboratories have become rather all-pervading for the ultra-trace analysis of elements, especially among those laboratories that work in the area of isotope geochemistry. The need 
for the control of analytical blanks has almost always been appreciated, but became the most important concern of analysts as new measurement technology opened the door to elemental measurements on amounts of substance equal to a nanogram or less. Since common laboratory environments expose samples to a contaminant deposition of up to one microgram in a 24 hour period, cleaner environments were documented as essential. In the 1960s, a number of laboratories applied clean air technology from the space and electronics industries to the chemical laboratory. The results from these pioneering efforts and the need to accurately measure elemental and isotopic compositions on the Apollo lunar samples led the National Bureau of Standards to build numerous complete clean air laboratories dedicated to sample preparation wet chemistry. These laboratories were simple but effective in design and have been extensively copied by other laboratories. By the early 1980s, the issue of air quality (the Class of the clean air) was beginning to be recognized by many as less important than the other issue in clean laboratory design. That is, contamination reduction may depend as much or more on keeping gross quantities of analyte elements out of the laboratory and preventing the formation of undesirable corrosion products. This was not news for the geochemistry community, but by the 1980s it had become a majority problem for trace element analytical chemistry, primarily because of the new focus of analytical chemistry on environmental measurements. The question now is where does clean laboratory design go to exact further improvements in laboratory performance. Part of the answer may lie in examining other trends in analytical chemistry and projecting how a clean laboratory might house them [24].

\subsection{Design and development of subsea pressure and temperature transmitters}

The design of a subsea electronic housing capable of withstanding $100 \mathrm{Mpa}$ differential of external or internal pressure is presented. This new housing permits the transmitter to be installed to depths of 9,000 meters below sea level; and provides a 100 Mpa secondary containment for the process fluid. Materials are selected throughout to provide maximum corrosion resistance. Glass to metal sealed electrical feed-throughs are utilized to eliminate transmitter danage in the case of a faulty or ruptured subsea cable. To meet industry standard installation practices, the subsea design incorporates A.P.I. type $6 \mathrm{~B}$ flanges into the high pressure process connections. Examination using finite element method and analytical calculations used in the design phase are discussed. Tests performed on various sub-assemblies are detailed, giving both empirical data and physical evidence to support the engineering investigation. Expected specifications, relating to the requirements of the problem definition, are cited for the new line of transmitters[25].

\subsection{Corrosion of $\mathrm{Pb}$-50In flip chip interconnections exposed to harsh environment}

Lead-indium alloys are an alternative to lead-tin solders usually used for interconnections in the electronics industry. Lead-indium alloys with 25 to 50 wt. \% In provide the advantage of a substantially lower procedure temperature and overall exhibit a much lower tendency to scavenge gold compared to $\mathrm{Pb}-\mathrm{Sn}$ solders with high $\mathrm{Pb}$ content. However, a corrosion problem has been identified in connection with $\mathrm{Pb}-50 \mathrm{In}$ solders, an alloy of attention owing to its thermal-fatigue resistance property. The author presents the results of a study conducted to gain a basic understanding of the nature and path of corrosion in $\mathrm{Pb}$-50In flip-chip connections exposed to an accelerated hostile-environment test simulating harsh industrial ambients. The key events in the corrosion process are identified and discussed[26].

\subsection{Considerations for surface mounting solder paste}

Solder paste as a joining material provides electrical, thermal and mechanical functions in an assembly. Its performance and superiority are vital to the integrity of solder joints, which in turn are significant to the overall function of the assembly. As the microelectronics/electronics industry continues to strive for 'quality' in every level of materials, designs and processes, and continues to grow and innovate, the demands on solder paste will be increasingly stringent[27].

\subsection{Electrochemical technology in electronic industry today and its future}

Recent electronics includes a broad range of machines such as various size computers with main memory, storage devices, input and output devices, telecommunication equipment, various purpose instruments and more or less sophisticated consumer electronic devices. Electrochemical processes are used today in almost every category of devices, machines and appliances: in the fabrication of conductors, contacts and connections, for mechanical wear-resistance, corrosion protection and decorative purposes. Often the electrochemical approach is the only one which can satisfy the need, gives the desired property or is cost competitive. Examples are given of some applications of electrochemical technology in electronics, of some attractive modifications of the elecrochemical processes to meet the needs of 
electronic devices and device fabrication. The future of electrochemistry and electrodeposition in electronics is discussed in view of problems experienced and in view of the advantages and the potential electrochemical technology offers by comparison to other technologies[28].

\subsection{Solid surfaces: Their atomic, electronic and macroscopic properties}

The free surface of a solid represents the most radical discontinuity in its structure that one can envisage. With crystalline solids the specific surface properties that arise involve . number of challenging physical problems as well as providing opportunities for exploitation in the electronics and chemical industries. For convenience one may divide these surface characteristics into atomic, electronic and macroscopic effects but, in fact, they are all interrelated. As far as atomic structure is concerned the atomic spacing of the surface layer is usually different from that of the bulk. Further, the atomic arrangement itself may be special (reconstruction). These differences affect the surface Debye temperature as well as the detailed processes involved in the adsorption of various or other deposited species. Because the electronic wave-functions are discontinued at the free surface, the electrons have energy states at the surface which are not the same as in the bulk. These surface energy states play a tremendously important parts in the electronics industry. They also influence the nature of interaction with adsorbed species and this in turn can crucially affect the catalytic activity of the surface, its chemical activity, oxidation and corrosion. Finally, the solid surface has a macroscopic surface energy which is involved in the thermodynamics of wetting and similar processes. It also affects diffusion which is important in the technological problem of sintering. At a different level of macroscopic concepts the surface is often a source of flaws or cracks and if the solid is brittle they may play a significant role in the overall strength of the solid. The surface may also contain emergent dislocations: these play a part in crystal growth as well as in the ductile strength of the surface layers [29].

\subsection{The National Electrical Code Procedure and Revisions}

A concise history is given of the development of the present committee structure for producing and revising the National Electrical Code. The procedure permits anyone to submit proposed revision of the code and provides a method of processing which insures a consensus and thus recognition as an American standard. A review is made of the schedule of revision and the steps taken to insure chance for review by industry before adoption. Technical committees are used to solve extraordinary problems where additional knowledge is needed. The intended function of tentative interim amendments and official interpretations are explained. Changes made in the 1965 edition of the National Electrical Code includes detailed coverage of multi-speed and partwinding motors, definition of unattended expansion of group motor applications, and motor disconnecting means. Other changes pertain to working space, 300-volt fuses, corrosion protection, new types of wire insulation, conduit fill and main protection for lighting, and appliance branch circuit panel boards [30].

\section{CONCLUSIONS}

Electronics has become all-pervading in our everyday lives. Occurring in all modern machines in the form of systems, functions, and components, it is gradually supplementing or replacing those functions previously carried out exclusively by mechanics, electromechanics, hydraulics, and pneumatics, by making the processes faster, more flexible, and safer in a quite impressive way The destruction of material properties due to environmental effects such as ultraviolet (UV) light, moisture, and oxygen has been a long-standing problem in electronic industry. To address this problem, materials are often coated with polymeric substances. Although polymers offer improved resistance against environmental degradation, they are not a comprehensive solution to overcoming the problem. Plastic encapsulated microcircuit (PEM) is widely used due to its great advantages in size, weight, cost and performance, especially in industries. For printed circuit board, surface finishes are better than just solderability conservation. The industrial use of $\mathrm{Zn}-\mathrm{Ni}$ alloys in steel objects - in which tribocorrosion must be taken into account - has significant importance, especially in the automotive industry, aircraft industry and electronics. Magnesium alloys have gained increased attention in recent years in automotive, electronics, and medical business. This is because of magnesium alloys have superior properties than aluminum alloys and steels in respects of their low density and high strength to weight ratio. It is usually recognized that vibration-induced fretting degradation can be a chief problem for connector systems used in vehicle electronics. An earlier initial study about vibration-induced fretting degradation was conducted for a blade/receptacle connector pair. Microelectronics and, chiefly, silicon integrated circuit microelectronics, has created astonishing capabilities over the last 40 years. The consumer industry is taking efficient measures to work safely and 
advantage from contemporary electronic gadgets, which eventually provide with a better and safer way of life. The industry introduces new, improved products almost annually, depending on the application, thereby significantly contributing to the economic growth.

\section{Acknowlegement}

The authors are thankful to their managements for their help and support.

\section{REFERENCES}

[1] S.Manoharan, C.Patel, P.McCluskey (2017) Advancements in silver wire bonding, ASME 2017 International Technical Conference and Exhibition on Packaging and Integration of Electronic and Photonic Microsystems, InterPACK 2017, collocated with the ASME 2017 Conference on Information Storage and Processing Systems.

[2] R.Asmatulu, S.I.Khan, M.L.Jenkinson (2016) Improving corrosion resistance via graphene nanocomposite coatings, Graphene Science Handbook: Size-Dependent Properties, 467-478.

[3] L.M.Toscano, E.Long (2015) A new surface finish for the electronics industry: Electroless nickel/immersion silver, 2014 9th International Microsystems, Packaging, Assembly and Circuits Technology Conference: Challenges of Change Shaping the Future, IMPACT 2014 - Proceedings 7048458, 372-378.

[4] Y.Li, G.Fu (2014) The influence of autoclave on plastic encapsulated microcircuit, Proceedings of 2014 Prognostics and System Health Management Conference, PHM 20146988144, 112-116.

[5] W.Wang, H.Zhang, Z.Wang (2014) Progress in magnesium alloys reinforced by long period stacking ordered structure, Xiyou Jinshu/Chinese Journal of Rare Metals, 38(1), 138-145.

[6] P.Zhu, Z.Cao, Y.Ye, M.Zhou, J. Zhou, (2013) Reuse of hazardous calcium fluoride sludge from the integrated circuit industry, Waste Management and Research, 31(11), 1154-1159.

[7] C.Mihail, V.Horaţiu, R.Vasile, G. Erno (2012) Effect of the intermediate layer composition on tribocorrosion behavior of zinc-nickel alloy, Korrozios Figyelo, 52(4), 82-85.

[8] X.Ma, D.G.Yang, G.Q.Zhang (2012) Decapsulation methods for $\mathrm{Cu}$ interconnection packages, ICEPTHDP 2012 Proceedings - 2012 13th International Conference on Electronic Packaging Technology and High Density Packaging, 6474864, 1387-1391.

[9] M.N.M.Ching, K.J.Lee (2011) Influence of nitrogen and forming gas towards palladium coated copper wire, 2011 IEEE 13th Electronics Packaging Technology Conference, EPTC 2011, 6184437, 318-323.

[10] C.D.Breach, T.Wai Mun, T.K.Lee, R.Holliday (2010) Moisture induced corrosion in gold and copper ball bonds, Proceedings of the IEEE/CPMT International
Electronics Manufacturing Technology (IEMT) Symposium 5746748.

[11] M.Ishak, K.Yamasaki, K.Maekawa (2010) Microstructure and corrosion behavior of laser welded magnesium alloys with silver nanoparticles, World Academy of Science, Engineering and Technology, 70, 354-359.

[12] S.P.Schroeder, G.K.Morris (2010) Nanofluids in a forced-convection liquid cooling system - Benefits and design challenges, 2010 12th IEEE Intersociety Conference on Thermal and Thermomechanical Phenomena in Electronic Systems, ITherm 2010, 5501326.

[13] S.Shrestha (2010) Magnesium and surface engineering, Surface Engineering, 26(5), 313-316.

[14] C.Brylinski (2009) Accounting for Heat Transfer Problems in the Semiconductor Industry, Topics in Applied Physics, 118, 367-386.

[15] C.Chen, G.T. Flowers, M. Bozack, J.Suhling (2009) Modeling and analysis of a connector system for the prediction of vibration-induced fretting degradation, Electrical Contacts, Proceedings of the Annual Holm Conference on Electrical Contacts 5284413, p.129-135.

[16] G.W.Parker, J.Walton (2007) Non-contact stray current measurements in a multi-line, multi-crossing pipeline corridor, NACE - International Corrosion Conference Series, 076491-0764918.

[17] D.G.Sediako, M.A.Gharghouri, R.B.Rogge, M.J. Watson (2007) Study of texture evolution during channel-die compression of MG-AL alloys by in-situ neutron diffraction, Magnesium Technologypp, p.351-356.

[18] L.S.Yeoh (2006) Reliability of microelectronic packages with tin-plated copper leads under high humidity operating environment, Proceedings of the Electronic Packaging Technology Conference, EPTC 4147360, 894-899.

[19] R.Reuss (2005) Large area distributed electronics, Digital Fabrication 2005 - Final Program and Proceedings, p.131.

[20] D.Scansen, R.Haythornthwaite, S.Brown (2005) Impact of Low $\mathrm{K}$ dielectrics on microelectronics reliability, Canadian Conference on Electrical and Computer Engineering, p.714-717.

[21] U.U.Tosun (2003) Who are we kidding? SMT Surface Mount Technology Magazine 17(11), 243249.

[22] G.Liu, C.Gao, J.Yang (2002) High corrosionresistant and long-life-span electroless nickel process, Metal Finishing, 100(3), 34-37.

[23] H.R.Majlesein, D.L.Mitchell, K.Bhattacharya, F.Pradeep, A.Singh, A.Anderson, F.James (1997) Primary response of high-aspect-ratio thermoresistive sensors, Proceedings of SPIE - The International Society for Optical Engineering, 3068, 388-394. 
[24] J.R.Moody (1996) Clean laboratories: Past, present and future, Journal of the Royal Society of Western Australia, 79(1), 29-32.

[25] S.Millar, G.James (1992) Design and development of subsea pressure and temperature transmitters, Proceedings of the International Offshore Mechanics and Arctic Engineering Symposium, 5(pt A), 1-11.

[26] K.J.Puttlitz (1989) Corrosion of Pb-50In flip chip interconnections exposed to harsh environment, Proceedings - Electronic Components and Technology Conference, p.438-444.
[27] J.S.Hwang (1988 ) Considerations for surface mounting solder paste, Brazing \& soldering, 14, 1321.

[28] L.T.Romankiw (1984) Electrochemical technology in electronic industry today and its future, Oberflache Zurich, 25(8), 238-247.

[29] D.Tabor (1981) Solid surfaces: Their atomic, electronic and macroscopic properties, Contemporary Physics, 22(2), 215-234

[30] R.Lloyd (1967) The National Electrical Code Procedure and Revisions, IEEE Transactions on Industry and General Applications, IGA, 3(3), 268271.

\section{IZVOD}

\section{PROBLEMI KOROZIJE U ELEKTRONSKIM SISTEMIMA}

Mikroelektronika $i$, uglavnom, silikonska mikroelektronika sa integrisanim krugom stvorili su zadivljujuće sposobnosti u poslednjih 40 godina. Brzo napredovanje u CMOS tranzistorskoj opremi, što dovodi do brzina gigaherca uobičajenih danas, zahteva velike promene u tehnologiji proizvodnje poluvodiča i širenje ambalaže kompatibilne sa visokom frekvencijom. Napredak optimizovane formulacije za oblaganje nikleom (EN) bez elektronike sa dugim vekom trajanja za deponovanje sa dobrom otpornošću na koroziju (CR). Elektro-taloženje legura Ni-P široko se koristi u raznim oblastima kao što su vazduhoplovstvo, automatizacija, elektronika, nuklearna, proizvodnja nafte i gasa $i$ industrija ventila. Olovni okvir je primarni metalurški interfejs paketa u mikroelektronskim uređajima koji omogućava spoljnu povezanost. Najviše preovlađujući materijal od olovnog okvira je bakar sa limenom oblogom. Tokom godina, galvanska korozija i oksidacija bakra dve su glavne brige o pouzdanosti za bilo koji paket mikroelektronike sa bakarnim olovnim okvirom, kada rade u okruženju sa visokom vlagom.

Ključne reči: elektronika, korozija, bimetalna korozija, elektronske komponente, vezivanje srebra.

Pregledni rad

Rad primljen: 13. 05. 2019.

Rad prihvaćen: 26. 05. 2019.

Rad je dostupan na sajtu: www.idk.org.rs/casopis

(c) 2019 Authors. Published by Engineering Society for Corrosion. This article is an open access article distributed under the terms and conditions of the Creative Commons Attribution 4.0 International license (https://creativecommons.org/licenses/by/4.0/) 